\title{
Influence of Solution Combination for Postharvest Treatment Stage on Vase Life of Cut Hydrangea Flowers (Hydrangea macrophylla cv. 'Verena')
}

\author{
Haejo Yang ${ }^{1}{ }^{\mathbb{D}}$, Sooyeon Lim ${ }^{1}$, Ji-Hyun Lee ${ }^{1}$, Ji-Weon Choi ${ }^{1}$ and Il-Sheob Shin ${ }^{2, *}$ \\ 1 Postharvest Technology Division, National Institute of Horticultural and Herbal Science, RDA, Wanju 55365, \\ Korea; gowh1231@korea.kr (H.Y.); sylim84@korea.kr (S.L.); leejh80@korea.kr (J.-H.L.); \\ jwcnpri@korea.kr (J.-W.C.) \\ 2 Pear Research Institute, National Institute of Horticultural and Herbal Science, RDA, Naju 58216, Korea \\ * Correspondence: shinis3@korea.kr
}

Citation: Yang, H.; Lim, S.; Lee, J.-H.; Choi, J.-W.; Shin, I.-S. Influence of Solution Combination for Postharvest Treatment Stage on Vase Life of Cut Hydrangea Flowers (Hydrangea macrophylla cv. 'Verena'). Horticulturae 2021, 7, 406. https://doi.org/ 10.3390/horticulturae7100406

Academic Editors: Maria Dulce Carlos Antunes, Custódia Maria Luís Gago, Adriana Guerreiro and Anastasios Darras

Received: 9 September 2021

Accepted: 14 October 2021

Published: 15 October 2021

Publisher's Note: MDPI stays neutral with regard to jurisdictional claims in published maps and institutional affiliations.

Copyright: (C) 2021 by the authors Licensee MDPI, Basel, Switzerland. This article is an open access article distributed under the terms and conditions of the Creative Commons Attribution (CC BY) license (https:/ creativecommons.org/licenses/by/ $4.0 /)$

\begin{abstract}
Vase life is one of the most important factors that determines the marketability of cut flowers and is greatly affected by the water balance. The vase life of cut hydrangea flowers varies greatly depending on the postharvest solution management. Therefore, this study investigated the vase life of freshly harvested hydrangea (Hydrangea macrophylla 'Verena') according to the three types of preservative solutions (tap water (TW), 1\% Chrysal Professional III (CPIII), 2\% sucrose + $250 \mathrm{mg} / \mathrm{L}$ 8-hydroxquinoline $+100 \mathrm{mg} / \mathrm{L}$ citric acid (SHQC)) and the combination solutions (pretreatment; TW, $0.1 \%$ Chrysal RVB (RVB), Floralife Quick Dip (FQ), transport; TW, CPIII, Floralife Clear (FC), preservative; CPIII, FC) for each distribution stage (pretreatment-transport-consumer). In the preservative comparison experiment, compared with the control, SHQC and CPIII significantly increased the vase life in 2019 (0.7 days, 3.4 days) and 2020 (1.4 days, 3.1 days), respectively. In the comparative experiment, by solution combination, the group (RVB, FQ) using the pretreatment significantly extended the vase life by 5.9 days and 4.6 days compared with the TW. These results confirm the importance of preservative solutions and pretreatment, suggesting that appropriate pretreatment and preservatives should be used to improve the marketability of cut hydrangea flowers.
\end{abstract}

Keywords: cut flower; preservative solution; pretreatment; transport; sucrose

\section{Introduction}

Hydrangea (Hydrangea spp.) is an ornamental plant widely used in the garden as a potted plant and also for cut flower production. Especially, Hydrangea macrophylla is the most cultivated cultivar among the Hydrangea species. Hydrangea inflorescences are classified into two types: hortensia and lace caps, depending on the arrangement of decorative and nondecorative flowers. Hortensia-type hydrangea, which has a high market share in the cut flower market, is classified into two stages: fresh stage and antique stage, depending on the harvest stage [1].

Vase life of cut hydrangea flowers harvested in the fresh stage is usually short, between 7 and 15 days [2]. Vase life is one of the most important quality factors affecting the marketability and customers' satisfaction of cut hydrangea flowers [3]. An important factor in determining the quality of cut flowers is known as vase life, which is affected by water absorption and evaporation [4]. Water absorption and evaporation of cut hydrangea flowers in all cut flowers is associated with catabolism, such as respiration, and decreases due to vascular occlusions by air embolism and microorganisms. In particular, microorganisms block the ends of cut flowers' stems, inhibiting solution uptake and shortening vase life [1,5]. To solve this problem, some studies have been conducted to extend the vase life of cut flowers by adding various preservatives to vase water [6-10]. In addition, the most important problem after harvesting cut flower hydrangea is that if the water supply is not 
maintained, air embolism may occur. Air embolism in xylem conduits can partially or completely block the water transport path between roots and sinks for water in plants [11]. Wilting is sometimes caused by air embolism and is a criterion for the end of vase life, and the vase life of cut hydrangeas is shortened due to sepal browning and wilting [12]. To prevent wilting by air embolism, cut flowers should be pretreated immediately after harvesting, have moisture managed during transport, and obtain preservative solution treatment at the consumer stage.

In many previous studies, aluminum sulfate, 8-hydroxyquinolin, 8-hydroxyquinolin sulfate (8-HQS), 8-hydroxyquinolin citrate, ethanol, and sodium hypochlorite are typically used as preservatives. In particular, 8-HQS is one of the essential preservatives used in cut flowers and has been reported to have a positive effect [13-15]. 8-HQS mainly acts as an antibacterial agent and has been reported as a mechanism to increase moisture by physiologically reducing stem blockage in sterile tissue absorption [16]. Sucrose is the most commonly used sugar to extend the vase life of cut flowers, and exogenous application of sucrose can supply large amounts of respiratory substrate to cut flowers and induce the flowering of flowers that are harvested at the bud stage. It is also known to improve water relationships by acting as osmotically active molecules [17].

However, although many studies on the effects of 8-HQS and sucrose have been reported, studies comparing the effects of 8-HQS and sucrose with preservatives commercially used in actual farmhouses are lacking.

The market for hydrangea is largely divided into domestic and export, and is commonly subdivided into harvest-transport-sale. In order to maintain the quality of cut flowers, proper vase solution treatment (pretreatment after harvesting, water container during transportation, preservative solution after purchase) should be performed at each distribution stage.

We aimed to compare the effects of currently used preservatives and scientifically reported preservatives on the vase life of cut hydrangea flowers, and further investigate the effect of each combination of pretreatment, transport, and preservative treatment.

\section{Materials and Methods}

\subsection{Plant Materials}

The hydrangea cultivar used in this experiment were those that are widely sold in Korea, and all were harvested in fresh stages. The cut hydrangea flower samples were 'Verena' grown in a farm in Gangjin, Jeollanam-do, South Korea ( $34^{\circ} 34^{\prime} 06^{\prime \prime} \mathrm{N} 126^{\circ} 50^{\prime} 08^{\prime \prime}$ E). The flowers were harvested at the commercial stage, where about $80 \%$ of the florets showed the colors of the cultivar in June of 2019 and 2020. The harvested flowers were immediately pretreated in a cold storage at $4{ }^{\circ} \mathrm{C}$ for $24 \mathrm{~h}$. After pretreatment, they were recut to a length $60 \mathrm{~cm}$ and put in a water container and transported to the postharvest laboratory within three hours. Then, the flowers were stored $72 \mathrm{~h}$ at $4{ }^{\circ} \mathrm{C}$ to transport conditions during simulated export. After simulated transport, the flower stems were recut to a length of $48 \mathrm{~cm}$ and five upper leaves were held on each stem for vase life evaluation.

\subsection{Treatment Solutions}

In this study, the first experiment is a comparative experiment with 3 types of preservation solutions, and the second experiment is a comparative experiment with 4 types of solution combinations for each postharvest treatment stage. The postharvest treatment stage was divided into a pretreatment stage at the farm, a transport stage during distribution, and a stage for preserving cut flowers after purchase.

For comparison by preservative solution treatment, the pretreatment and transportation solution were treated with tap water (TW), and then the preservation solution was used. The preservative solutions used were 1\% Chrysal Professional III (CPIII), 2\% sucrose $+250 \mathrm{mg} / \mathrm{L}$ 8-hydroxquinoline $+100 \mathrm{mg} / \mathrm{L}$ citric acid (SHQC), and TW as control. Preservative solution treatment was carried out by putting $700 \mathrm{~mL}$ of preservative solution prepared in advance in a glass bottle $(1000 \mathrm{~mL})$. 
For comparison by solution combinations for each postharvest treatment stage, the pretreatment solution used were $0.1 \%$ Chrysal RVB (RVB), Floralife Quick Dip (FQ), and TW as control. For pretreatment, after the hydrangea flowers were harvested, they were immediately transferred to storage set at $4{ }^{\circ} \mathrm{C}$ and immersed in the pretreatment solution for $24 \mathrm{~h}$. The transport solution used were CPIII, Floralife Clear (FC), and TW as control. The pretreated flowers were put in a water container containing transport solution, and then packed in a cardboard box and stored at $4{ }^{\circ} \mathrm{C}$ for $72 \mathrm{~h}$, which was simulated transport with consideration for the transport period from packaging to sales. The preservative solution used were CPIII and FC. All solutions were prepared fresh at the initiation of the study. The conditions of the vase life evaluation room included a fluorescent lamp turned on for $12 \mathrm{~h}$ from $6 \mathrm{am}$ to $6 \mathrm{pm}$ every day with a room temperature of $22 \pm 1^{\circ} \mathrm{C}$, and relative humidity of $60 \pm 5 \%$.

\subsection{Relative Fresh Weight, Solution Uptake, Water Balance, and Vase Life}

Fresh weight and solution uptake were measured once every 2 days. Fresh weight was calculated by subtracting the weight of the vase and solution from the total weight of the vase, solution, and flower. Relative fresh weight was calculated as the rate of fresh weight change, which was calculated as a percentage of fresh weight at the day of measurement compared with fresh weight at the day of initial.

$$
\begin{gathered}
\text { Relative fresh weight }(\% \text { of initial })=\left(\mathrm{W}_{\mathrm{t}} / \mathrm{W}_{0}\right) * 100 \\
\mathrm{~W}_{\mathrm{t}}=\text { the weight of flower stem }(\mathrm{g}) \text { at the day of measurement } \\
\mathrm{W}_{0}=\text { the weight of flower stem }(\mathrm{g}) \text { at the day of initial }
\end{gathered}
$$

Solution uptake was investigated by subtracting the weight of the vase and solution on the day of measurement from the weight of the vase and solution on the previous day. Total solution uptake was calculated by adding up all daily solution uptakes. Water balance was investigated by subtracting transpiration from solution uptake, and transpiration was investigated by subtracting the total weight (sum of the weight of the vase, solution, and cut flower) on the day of measurement from the total weight on the previous day. Vase life was defined by the duration from the initial experiment to the occurrence of wilting, browning, and drying. The degree of flower wilting, browning, drying and vase life of flowers was determined according to the morphological stages and appearance of symptoms such as drying, brown edges, wilting flower, and bent neck (Figure 1).

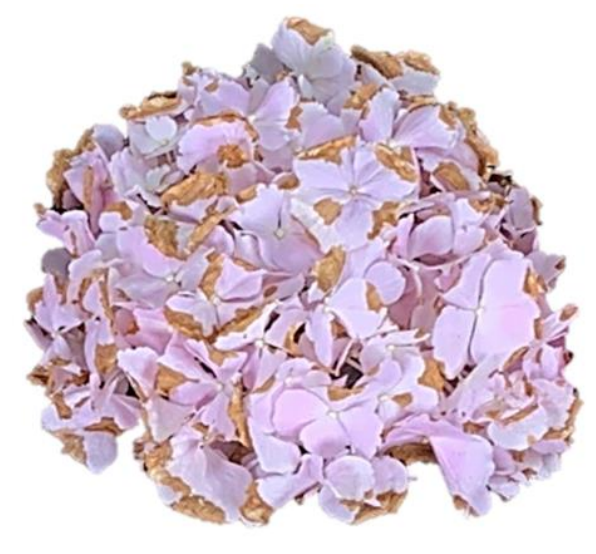

(a)

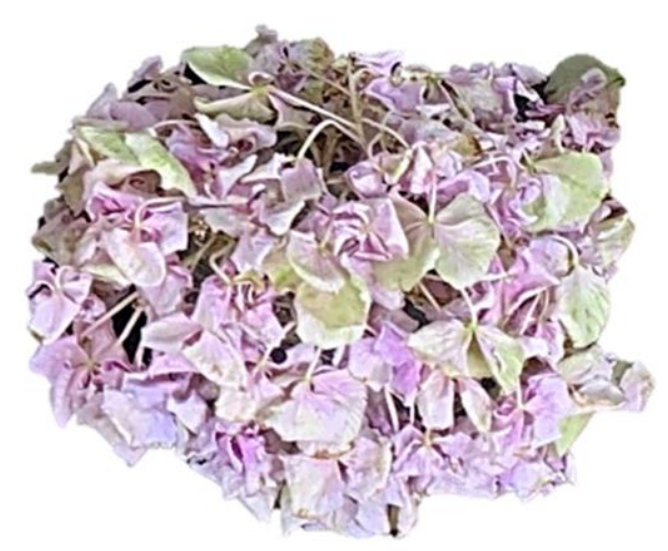

(b)

Figure 1. The main senescence symptoms of cut hydrangea flowers 'Verena' (a) browning (b) wilting. 


\subsection{Statistical Analysis}

The experiment with preservative solution 3 treatment and postharvest solution combination 4 treatments was conducted in completely randomized design (CRD) with three replicates and three flowers for each replication. For statistical analysis, data were subjected to Brown-Forsythe and Welch analysis of variance (ANOVA) using the SPSS 20 (SPSS Inc., Chicago, IL, USA), while the significance of differences was assessed using Duncan's multiple range test $(p<0.05)$.

\section{Results}

\subsection{Relative Fresh Weight Due to Preservative Solution}

Fresh weight results were expressed as relative fresh weight with the results for each preservative solution treatment shown in Figure 2. Relative fresh weight in SHQC treatment increased sharply until 8 days (2019) and 10 days (2020), respectively (Figure 2). As a result, in 2019, TW and CPIII treatment maintained, as compared with initial weights, whereas the SHQC treatment increased at 8 days (Figure 2a). As a result, in 2020, a pattern similar to the 2019 result was shown, and the TW and CPIII treatment maintained the initial weight, while the SHQC treatment increased the fresh weight compared with the initial weight. (Figure 2b).

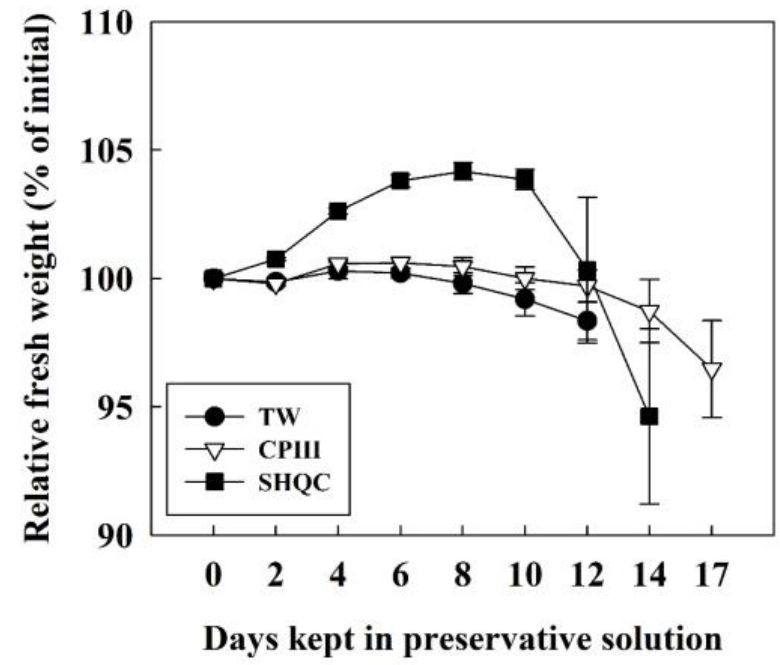

(a)

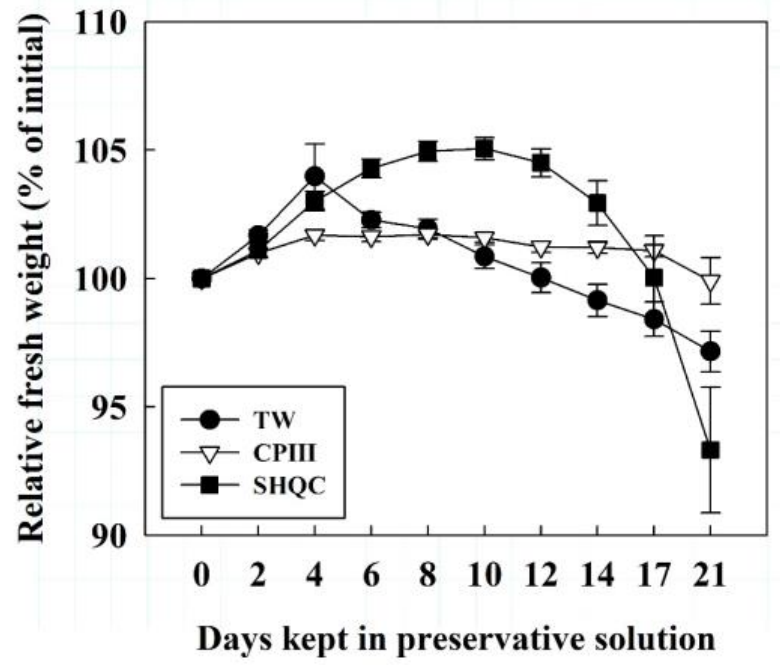

(b)

Figure 2. Changes in the relative fresh weight of cut hydrangea flowers 'Verena' kept in each preservative solution treatment in (a) 2019 and (b) 2020. Vertical bars indicate standard deviation of means ( $n=9$ ). TW, tap water; CPIII, $1 \%$ Chrysal Professional III; and SHQC, 2\% sucrose $+250 \mathrm{mg} / \mathrm{L}$ 8-hydroxquinoline $+100 \mathrm{mg} / \mathrm{L}$ citric acid.

\subsection{Solution Uptake and Total Solution Uptake Due to Preservative Solution}

Solution uptake decreased until the 10th day after preservative solution treatment in all treatments, and TW treatment was the the lowest until 6 days after treatment, but there was no significant difference between treatments. In addition, CPIII treatment and SHQC treatment maintained solution uptake as much as the initial solution uptake level until the end of vase life (Figure 3a). Total solution uptake in 2019 was $199.08 \mathrm{~g} / \mathrm{stem}$ in CPIII treatment, which was higher than tap water treatment $(138.00 \mathrm{~g} / \mathrm{stem})$ and SHQC treatment (163.54 g/stem) (Table 1). As a result, in 2020, the initial solution uptake of the three treatments was 15.3,15.9, and $16.3 \mathrm{~g} / \mathrm{stem}$, respectively, and the difference in absorption between TW, CPIII, and SHQC treatments was $0.6 \sim 1 \mathrm{~g} / \mathrm{stem}$, which was similar. Changes in solution uptake during the preservation period of cut flowers were 8.9, 11.4, and $12.0 \mathrm{~g} / \mathrm{stem}$ at 19 days, respectively. The difference in solution uptake between TW and treatment with CPIII and SHQC ranged from $2.5 \mathrm{~g} / \mathrm{stem}$ to $3.1 \mathrm{~g} / \mathrm{stem}$, and there was 
a statistically significant difference between the control and treatment groups (Figure 3b). In 2020, the total solution uptake of CPIII and SHQC was 135.28 and $132.71 \mathrm{~g} / \mathrm{stem}$, respectively, which was statistically significantly higher than TW treatment (Table 1).

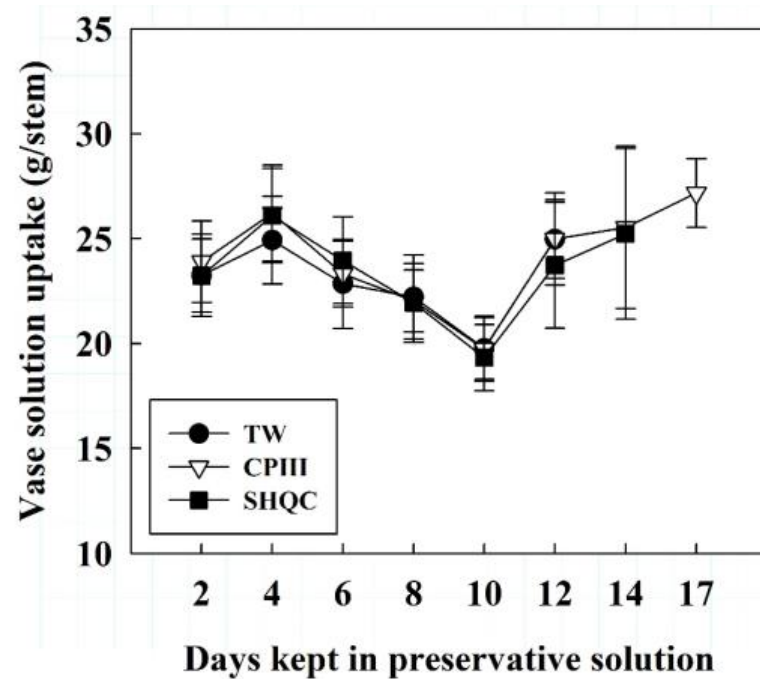

(a)

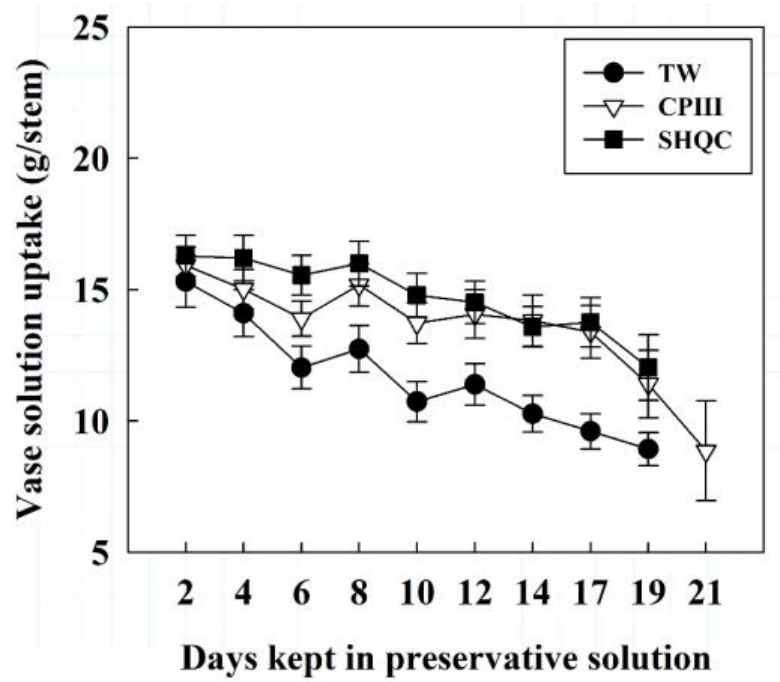

(b)

Figure 3. Changes in the vase solution uptake of cut hydrangea flowers 'Verena' kept in each preservative solution treatment in (a) 2019 and (b) 2020. Vertical bars indicate standard deviation of means ( $n=9)$. TW, tap water; CPIII, $1 \%$ Chrysal Professional III; and SHQC, $2 \%$ sucrose $+250 \mathrm{mg} / \mathrm{L}$ 8-hydroxquinoline $+100 \mathrm{mg} / \mathrm{L}$ citric acid.

Table 1. Total solution uptake of cut hydrangea flowers 'Verena' kept in each preservative solution treatment in 2019 and 2020.

\begin{tabular}{|c|c|c|c|c|c|c|}
\hline Year & $\begin{array}{l}\text { Pretreatment } \\
\text { Solution }\end{array}$ & $\begin{array}{l}\text { Transport } \\
\text { Solution }\end{array}$ & $\begin{array}{l}\text { Preservative } \\
\text { Solutions }\end{array}$ & $\begin{array}{c}\text { Total } \\
\text { Solution } \\
\text { Uptake } \\
\text { (g/stem) }\end{array}$ & F/p Value & $\begin{array}{c}\text { Brown- } \\
\text { Forsythe } \\
\text { Value }\end{array}$ \\
\hline \multirow{3}{*}{2019} & TW & TW & $\mathrm{TW}^{\mathrm{z}}$ & $138.00 \mathrm{~b}^{\mathrm{y}}$ & \multirow{3}{*}{$4.759 / 0.058^{\text {ns x }}$} & \multirow{3}{*}{0.095} \\
\hline & TW & TW & CPIII & $199.08 \mathrm{a}$ & & \\
\hline & TW & TW & SHQC & $163.54 \mathrm{ab}$ & & \\
\hline \multirow{3}{*}{2020} & TW & TW & TW & $105.12 \mathrm{~b}$ & \multirow{3}{*}{$4.206 / 0.27 *$} & \multirow{3}{*}{0.028} \\
\hline & TW & TW & CPIII & $135.28 \mathrm{a}$ & & \\
\hline & TW & TW & SHQC & $132.71 \mathrm{a}$ & & \\
\hline
\end{tabular}

z Abbreviations: TW = tap water; CPIII = 1\% Chrysal Professional III; SHQC = 2\% sucrose + 250 mg/L 8hydroxquinoline $+100 \mathrm{mg} / \mathrm{L}$ citric acid. y a, ab, b: Mean separation within columns by Duncan's multiple ranges test at $p<0.05$. ${ }^{x}$ Minimum vase life and maximum vase life (day). ns, ${ }^{*}$ : Nonsignificant or significant at $p<0.05$, respectively.

\subsection{Water Balance Due to Preservative Solution}

The water balance results according to the preservative solution treatment showed a similar trend to the 2019 and 2020 results, and the water balance in the SHQC treatment was maintained longer than that of other treatments. The number of days to maintain the water balance was the date at which water balance value changed from a positive value to a negative value. As a result, in 2019, the number of days to maintain water balance in SHQC treatment was 8, which was maintained for 2-4 days longer than 6 days for CPIII treatment, and 4 days for TW (Figure 4a). In the study conducted in 2020, the number of days of maintaining water balance in SHQC treatment was 10, which was 2-4 days longer than 8 days for CPIII treatment, and 6 days for TW (Figure $4 \mathrm{~b}$ ). 


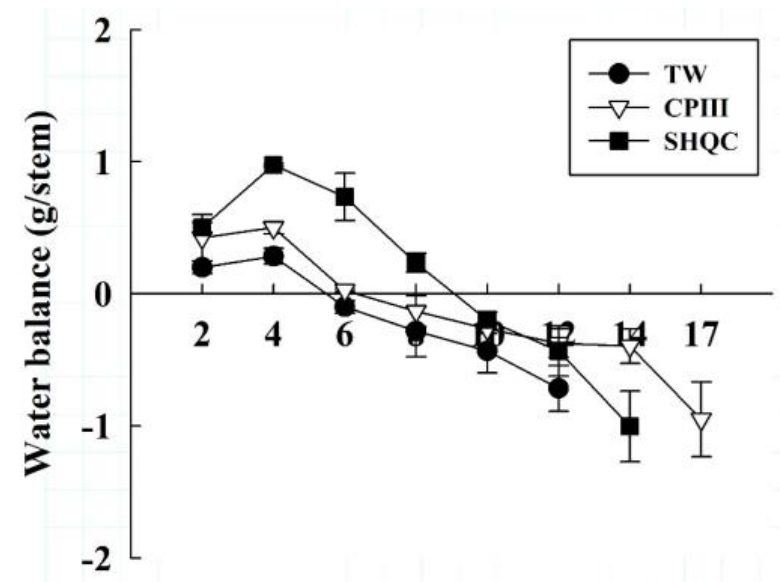

Days kept in preservative solution

(a)

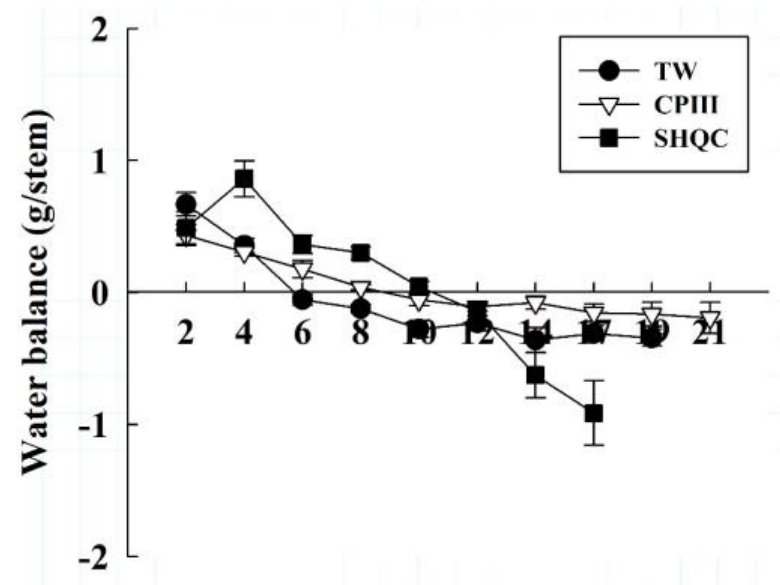

Days kept in preservative solution

(b)

Figure 4. Changes in the water balance of cut hydrangea flowers 'Verena' kept in each preservative solution treatment in (a) 2019 and (b) 2020. Vertical bars indicate standard deviation of means ( $n=9)$. TW, tap water; CPIII, $1 \%$ Chrysal Professional III; and SHQC, 2\% sucrose + $250 \mathrm{mg} / \mathrm{L}$ 8-hydroxquinoline $+100 \mathrm{mg} / \mathrm{L}$ citric acid.

\subsection{Vase Life Due to Preservative Solution}

The use of a preservative was effective in extending the vase life following the treatment with a preservative solution (Table 2). As a result, in 2019, the vase life of CPIII treatment and SHQC treatment was extended by 0.7-3.4 days as compared with the TW treatment. The minimum vase life of CPIII treatment was 18 days and the maximum vase life was 23 days, which exceeded the vase life of TW and SHQC treatment. In the 2020 results, the vase life was extended with the CPIII treatment and SHQC treatment as compared with the TW. In both 2019 and 2020, CPIII treatment and SHQC treatment with a preservation solution at the consumer stage was effective in extending the vase life of cut hydrangea flowers.

Table 2. Vase life and main factor of senescence of cut hydrangea flowers 'Verena' kept in each preservative solution treatment in 2019 and 2020.

\begin{tabular}{|c|c|c|c|c|c|c|c|c|c|}
\hline \multirow{2}{*}{ Year } & \multirow{2}{*}{$\begin{array}{l}\text { Pretreatment } \\
\text { Solution }\end{array}$} & \multirow{2}{*}{$\begin{array}{l}\text { Transport } \\
\text { Solution }\end{array}$} & \multirow{2}{*}{$\begin{array}{l}\text { Preservative } \\
\text { Solutions }\end{array}$} & \multicolumn{4}{|c|}{ Vase Life (days) } & \multirow{2}{*}{ F/p Value } & \multirow{2}{*}{$\begin{array}{c}\text { Brown- } \\
\text { Forsythe } \\
\text { Value }\end{array}$} \\
\hline & & & & Average & Min. ${ }^{x}$ & Max. & $\mathbf{M F}^{\mathbf{r}}$ & & \\
\hline \multirow{3}{*}{2019} & $\mathrm{TW}^{\mathrm{z}}$ & TW & TW & $17.3 \mathrm{~b}^{\mathrm{y}}$ & 17 & 18 & B & \multirow{3}{*}{$3.652 / 0.092^{\mathrm{ns}}$} & \multirow{3}{*}{0.163} \\
\hline & TW & TW & CPIII & $20.7 \mathrm{a}$ & 18 & 23 & $\mathrm{~B} / \mathrm{W}$ & & \\
\hline & TW & TW & SHQC & $18.0 \mathrm{ab}$ & 17 & 19 & W & & \\
\hline \multirow{3}{*}{2020} & TW & TW & TW & $20.9 \mathrm{~b}$ & 20 & 21 & B & \multirow{3}{*}{$6.316 / 0.006^{* *}$} & \multirow{3}{*}{0.012} \\
\hline & TW & TW & CPIII & $24.0 \mathrm{a}$ & 21 & 28 & $\mathrm{~B} / \mathrm{W}$ & & \\
\hline & TW & TW & SHQC & $22.3 \mathrm{ab}$ & 20 & 24 & $\mathrm{~W} / \mathrm{B}$ & & \\
\hline
\end{tabular}

${ }^{\mathrm{z}}$ Abbreviations: TW = tap water; CPIII $=1 \%$ Chrysal Professional III; SHQC $=2 \%$ sucrose $+250 \mathrm{mg} / \mathrm{L}$ 8-hydroxquinoline $+100 \mathrm{mg} / \mathrm{L}$ citric acid. ${ }^{\mathrm{y}} \mathrm{a}, \mathrm{ab}, \mathrm{b}$ : Mean separation within columns by Duncan's multiple ranges test at $p<0.05 .{ }^{\mathrm{x}}$ Minimum vase life and maximum vase life (day). ${ }^{\mathrm{r}}$ Main factor in determining the vase life of cut flowers (B, browning; $\mathrm{W}$, wilting). ns, ${ }^{* *}$ : Nonsignificant or significant at $p<0.01$, respectively.

\subsection{Relative Fresh Weight Due to Combination of Postharvest Solution}

The results of relative fresh weight by solution combination for each postharvest treatment stage are shown in Figure 5a. There was a slight difference in the maintenance period of fresh weight for each treatment. As compared with other treatments, the RVBCPIII-CPIII combination had the longest fresh weight maintenance period of 23 days and showed a difference of about 5 days. During vase life, the RVB-CPIII-CPIII combination was higher than those without pretreatment. It was similar to the FQ-FC-FC combination, and there was no significant difference. 


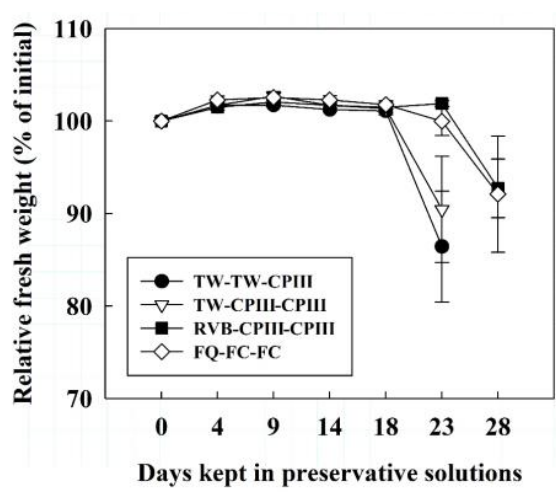

(a)

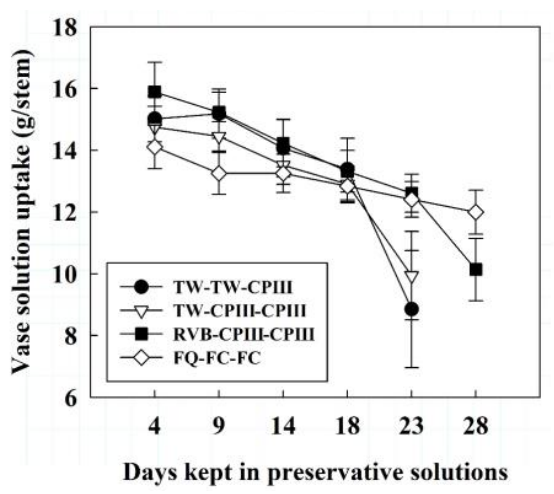

(b)

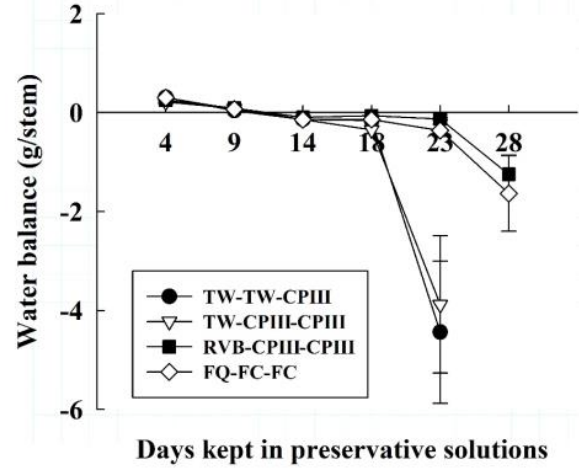

(c)

Figure 5. Changes in the relative fresh weight in (a) vase solution uptake, (b) water balance, and (c) cut hydrangea flowers 'Verena' by solution combination for each postharvest treatment stage in 2020. Vertical bars indicate standard deviation of means $(n=9)$. TW, tap water; CPIII, $1 \%$ Chrysal Professional III; RVB, 0.1\% Chrysal RVB; FQ, Floralife Quick Dip; and FC, Floralife Clear. The order of TW-TW-CPIII indicates the order of pretreatment solution, transport solution, and preservation solution.

\subsection{Solution Uptake and Total Solution Uptake Due to Combination of Postharvest Solution}

The results of solution uptake and total solution uptake by solution combination for each postharvest treatment stage are shown in Table 3 and Figure 5b. Solution uptake gradually decreased during the preservation period of cut flowers commonly for all treatments. In particular, the solution uptake of cut flowers treated with the TW-TW-CPIII and TW-CPIII-CPIII combination decreased sharply from 18 days. On the other hand, the RVBCPIII-CPIII combination and FQ-FC-FC combination maintained solution uptake during vase life as compared with other combinations. This finding was statistically significant both by using Duncan's multiple range test between absolute values, and with repeated measurements. The total solution uptake by each postharvest solution was $164.92 \mathrm{~g} / \mathrm{stem}$ in the RVB-CPIII-CPIII combination, which was the highest as compared with other treatments, but there was no statistically significant difference between treatments.

Table 3. Total solution uptake of cut hydrangea flowers 'Verena' by solution combination for each postharvest treatment stages in 2020 .

\begin{tabular}{cccccc}
\hline $\begin{array}{c}\text { Pretreatment } \\
\text { Solutions }\end{array}$ & $\begin{array}{c}\text { Transport } \\
\text { Solutions }\end{array}$ & $\begin{array}{c}\text { Preservative } \\
\text { Solutions }\end{array}$ & $\begin{array}{c}\text { Total Solution } \\
\text { Uptake } \\
\text { (g/stem) }\end{array}$ & F/ $p$ Value & $\begin{array}{c}\text { Brown- } \\
\text { Forsythe } \\
\text { Value }\end{array}$ \\
\hline TW TW $_{\text {TW }}$ & TW & CPIII & $141.18 \mathrm{a}$ y & & \\
RVB & CPIII & CPII & $143.78 \mathrm{a}$ & $2.024 / 0.130 \mathrm{~ns}$ & 0.133 \\
FQ & FC & CPIII & $164.98 \mathrm{a}$ & & \\
\hline
\end{tabular}

${ }_{\bar{z}}$ Abbreviations: TW = tap water; CPIII = $1 \%$ Chrysal Professional III; RVB = 0.1\% Chrysal RVB; FQ = Floralife Quick Dip; FC = Floralife Clear. ${ }^{\mathrm{y}}$ a: Mean separation within columns by Duncan's multiple ranges test at $p<0.05$.). ns: Nonsignificant at $p<0.01$, respectively.

\subsection{Water Balance Due to Combination of Postharvest Solution}

The results of water balance according to the solution management in the overall process from preharvest treatment to preservation solution showed a dramatic effect depending on the treatment (Figure 5c). The effect of maintaining the water balance according to the treatment of the transport solution used in the distribution stage was insignificant. The number of days for maintaining water balance between the TW-TWCPIII combination and the TW-CPIII-CPIII combination was the same 9 days; therefore there was no difference between TW and CPIII used as a transport solution. However, due to the use of pretreatment, the number of days for maintaining water balance was slightly extended. The number of days for maintaining water balance of the RVB-CPIII-CPIII and 
the FQ-FC-FC combination with the pretreatment was 23 , which was extended by 5 more days than the TW-TW-TW and the TW-CPIII-CPIII combination without pretreatment. In addition, there was a difference in the time when the water balance value rapidly decreased, depending on whether or not pretreatment was used. The combination with pretreatments such as RVB and FQ started to decrease from day 18, while the combination without pretreatment decreased sharply from day 18 .

\subsection{Vase Life Due to Combination of Postharvest Solution}

The effect of pretreatment performed in the postharvest treatment stage was clearly different in the results of vase life according to the 4 groups of postharvest solution combinations (Table 4, Figure 6). The average vase life of the group pretreated with RVB and FQ were 29.9 and 28.6 days, respectively, which was longer than that of the group without pretreatment. In particular, the vase life of the RVB-CPIII-CPIII combination was 27 days at the minimum and 35 days at the maximum, which exceeded the vase life range of the TW-TW-CPIII combination. Through these results, it was confirmed that the use of an appropriate pretreatment agent is an important factor to extend vase life and improve quality.

Table 4. Vase life and main factor of senescence of cut hydrangea flowers 'Verena' by solution combination for each postharvest treatment stage in 2020.

\begin{tabular}{|c|c|c|c|c|c|c|c|c|}
\hline \multirow{2}{*}{$\begin{array}{l}\text { Pretreatment } \\
\text { Solution }\end{array}$} & \multirow{2}{*}{$\begin{array}{l}\text { Transport } \\
\text { Solution }\end{array}$} & \multirow{2}{*}{$\begin{array}{l}\text { Preservative } \\
\text { Solution }\end{array}$} & \multicolumn{4}{|c|}{ Vase Life (Days) } & \multirow{2}{*}{ F/ $p$ Value } & \multirow{2}{*}{$\begin{array}{c}\text { Brown-Forsythe } \\
\text { Value }\end{array}$} \\
\hline & & & Average & Min. $^{x}$ & Max. & $\mathrm{MF}^{\mathrm{r}}$ & & \\
\hline $\mathrm{TW}^{\mathrm{z}}$ & TW & CPIII & $24.0 \mathrm{~b}^{\mathrm{y}}$ & 21 & 28 & $\mathrm{~W}$ & \multirow{4}{*}{$9.674 / 0.000 * * *$} & \multirow{4}{*}{0.000} \\
\hline TW & CPIII & CPIII & $25.0 \mathrm{~b}$ & 20 & 29 & B & & \\
\hline RVB & CPIII & CPIII & $29.9 \mathrm{a}$ & 27 & 35 & $\mathrm{~B}$ & & \\
\hline $\mathrm{FQ}$ & FC & FC & $28.6 \mathrm{a}$ & 23 & 31 & $\mathrm{~B}$ & & \\
\hline
\end{tabular}

${ }^{\mathrm{z}}$ Abbreviations: TW $=$ tap water; CPIII $=1 \%$ Chrysal Professional III; RVB $=0.1 \%$ Chrysal RVB; FQ = Floralife Quick Dip; and FC = Floralife Clear. ${ }^{\mathrm{y}}$ a: Mean separation within columns by Duncan's multiple ranges test at $p<0.05 .{ }^{\mathrm{x}}$ Minimum vase life and maximum vase life (day).

${ }^{\mathrm{r}}$ Main factor in determining the vase life of cut flowers (W, wilting; $\mathrm{B}$, browning). ${ }^{* * *}$ : significant at $p<0.001$, respectively.
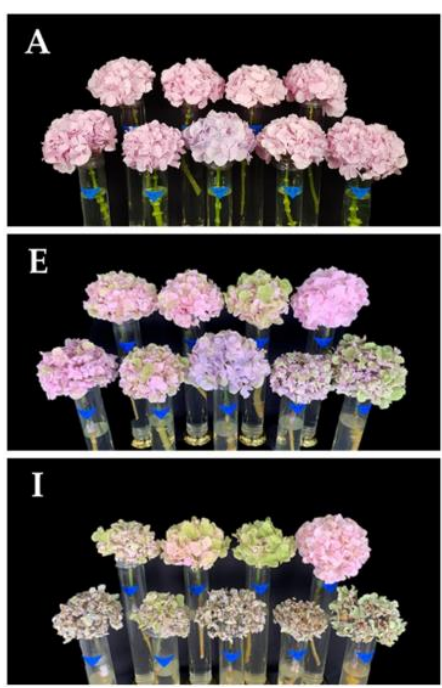
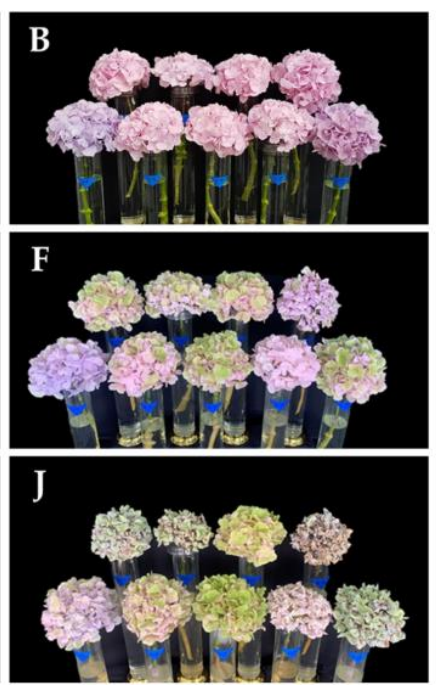
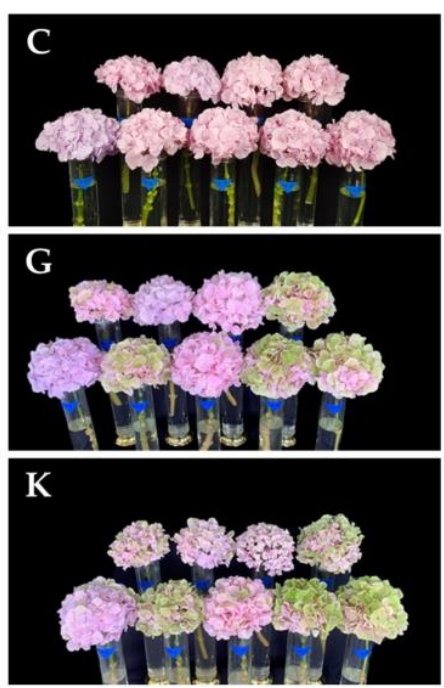
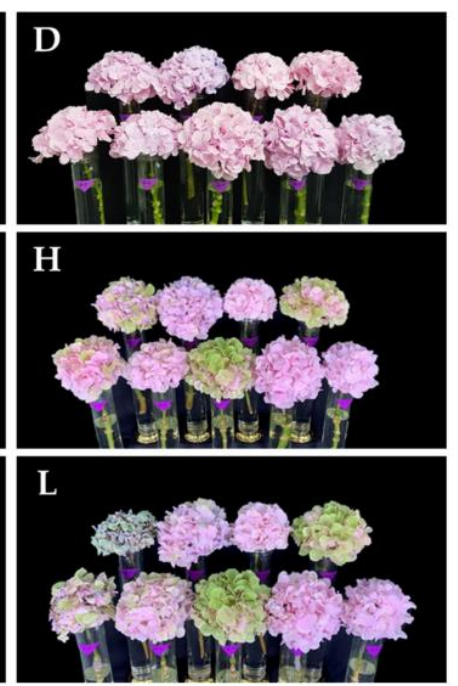

Figure 6. Appearance of cut hydrangea flowers 'Verena' by solution combination for each postharvest treatment stage in 2020. (A-D): First day after preservative solution, (E-H): 22nd day after preservative solution, (I-L): 29th day after preservative solution (A,E,I): TW-TW-CPIII, (B,F,J): TW-CPIII-CPIII, (C,G,K): RVB-CPIII-CPIII, (D,H,L): FQ-FC-FC.

\section{Discussion}

Cut hydrangea flowers are sensitive to water stress, and when water is insufficient, the water balance of the calyx changes to a negative value. The main causes of water stress are interruption of water supply and vascular occlusion at the tip of the stem [18]. Most cut flowers, including cut hydrangea flowers, have a high initial solution uptake rate, 
but decrease over time, mainly due to vascular blockage by microorganisms and air embolism [9]. The impact of kept water relations on extending the vase life is constructed on the conclusion that cut hydrangeas are sensitive to water shortage caused by disturbing the postharvest water balance $[9,12,19]$. If these causes persist, they wither and the quality of the cut flowers deteriorates, which is the standard for the end of the vase life [1]. Asrar [13] reported that solution uptake through preservative treatment improved the water balance and freshness of flowers and reduced premature wilting, thereby improving the vase life of cut flowers, which is similar to our comparative results of preservative treatment. In our study, we observed the vase life of cut hydrangea flowers according to the combination of a preservation solution at the consumer stage and solution combination for each postharvest treatment stage after harvest for the purpose of improving the marketability of cut hydrangea flowers. For hydrangeas grown in Korea, it usually takes 2-3 days for export to the destination country. During this period, water management should be focused on the pretreatment stage immediately after harvest and the transportation stage. Pretreatment immediately after harvest is an essential step as it artificially supplies nutrient moisture to cut flowers whose supply of moisture and nutrients is interrupted [20]. In addition, the use of preservatives as a post-treatment concept to help prolong the flower viewing period at the consumer stage is also effective in extending the vase life. In particular, the various chemical solutions used in this study, such as RVB, CPIII, SHQC, FQ, and FC, generally have a specific purpose, so proper use is required. Previous studies reported that there was a strong correlation between solution uptake and fresh weight $[5,21]$, and the combined effect of sucrose and antibacterial agents on the fresh weight of cut flowers was significantly greater than that of single treatment [22]. Sucrose supply is known to increase vase life, and it has been reported that it may act as an osmotic active molecule constituting a water relationship, as well as a nutrient source for tissues [23-25]. Similar to these reports, in our study, RVB as a pretreatment and SHQC as a preservative solution absorbed more solution than TW treatment and improved water balance. In addition, SHQC treatment with $2 \%$ sucrose significantly increased the fresh weight as compared with TW treatment. These results at fresh weight are similar to those of solution uptake positively affected by 8-HQ with $2 \%$ sucrose. Ku and Cho [26] also used 8-HQS to increase vase life of cut hydrangeas. They performed three different experiments [ $1 \%$ and $3 \%$ sucrose $+250 \mathrm{mg} / \mathrm{L} 8$-HQS, varying $\mathrm{pH}$ levels (3.5-5.5 and 7.5), organic acids (citric and ascorbic)] and $3 \%$ sucrose $+250 \mathrm{mg} / \mathrm{L}$ 8-HQS. As a result, it was reported that 8-HQS (pH 3.5), or 3\% sucrose + $250 \mathrm{mg} / \mathrm{L}$ 8-HQS $+100 \mathrm{~mL}$ citric acid, was effective in improving the cut flower quality of hydrangeas. As such, the maintenance of the water balance according to the increase in solution uptake and the decrease in transpiration can have a positive effect on fresh weight by preventing the water loss of cut flowers. In addition, pretreatment using RVB, which consists of sucrose and disinfectant, and transportation and preservation processing using CPIII, which is used for a different purpose than RVB, is one of the postharvest management technologies that must be performed in the entire distribution process, from harvesting to sales. When managing in this way, it was confirmed that the effect of maintaining the marketability was excellent.

\section{Conclusions}

This study was set up to highlight the importance of using the right pretreatment and preservatives at farms and in distribution stages by showing the potential effects on maintaining the commerciality of cut hydrangea flowers and extending the vase life. In the preservation solution comparison experiment, treatment with $1 \%$ CPIII and SHQC significantly extended the vase life of cut hydrangea flowers by 3.1 days and 1.4 days, respectively, as compared with control. In the comparative experiment of solution combination for each postharvest treatment stage, the pretreatment group using RVB and FQ significantly extended the vase life of cut hydrangea flowers to 5.9 and 4.6 days, respectively, as compared with control group (TW-TW-CPIII). These results show that using a pretreatment solution is effective in improving the quality of cut hydrangea flowers after long-term distribution. 
However, SHQC used in the preservation solution comparison experiment was conducted to explore the possibility of replacing commercial preservatives, but did not obtain beneficial results, such as extending the vase life of cut hydrangea flowers and maintaining freshness. Therefore, new research on finding the optimal combination of sucrose, 8-HQS, and citric acid, and developing eco-friendly pretreatments and preservatives using natural materials should be performed.

Author Contributions: Conceptualization, I.-S.S. and H.Y.; methodology, I.-S.S. and H.Y.; validation, J.-H.L., S.L. and J.-W.C.; investigation, H.Y.; resources, I.-S.S.; data curation, J.-H.L., S.L. and J.-W.C.; writing—original draft preparation, H.Y.; writing—review and editing, I.S.S. and H.Y.; visualization, H.Y.; supervision, I.-S.S.; project administration, I.-S.S. All authors have read and agreed to the published version of the manuscript.

Funding: This work was carried out with the support of "Research Program for Agriculture Science \& Technology Development (Project No. PJ01434201)" Rural Development Administration, Korea.

Data Availability Statement: Data is contained within the article. The data presented in this study are available in article.

Acknowledgments: This study was supported by (2021) the RDA Fellowship Program of (National Institute of Horticultural \& Herbal Science), Rural Development Administration, Korea.

Conflicts of Interest: The authors have declared that no conflicts of interest exist.

\section{References}

1. Kitamura, Y.; Kato, Y.; Yasui, T.; Aizawa, H.; Ueno, S. Relation between increases in stomatal conductance of decorative sepals and the quality of antique-stage cut hydrangea flowers. Hort. J. 2017, 86, 87-93. [CrossRef]

2. Thomas, D.; Gollnow, B. What Cut Flower Is That? The Essential Care and Handling Guide for Cut Flower Professionals; Kingston, Australia Government, Rural Industries Research and Development Corporation: Kingston, Australia, $2014 ;$ p. 197.

3. da Costa, L.C.; Finger, F.L. Flower opening and vase life of gladiolus cultivars: The sensitivity to ethylene and the carbohydrate content. Ornam. Hortic. 2016, 22, 147-153. [CrossRef]

4. Kitamura, Y.; Ueno, S. Inhibition of transpiration from the inflorescence extends the vase life of cut hydrangea flowers. Hort. J. 2015, 84, 156-160. [CrossRef]

5. Alaey, M.; Babalar, M.; Naderi, R.; Kafi, M. Effect of pre-and postharvest salicylic acid treatment on physio-chemical attributes in relation to vase-life of rose cut flowers. Postharvest Biol. Technol. 2011, 61, 91-94. [CrossRef]

6. Abreu, M.E.; Munné-Bosch, S. Salicylic acid may be involved in the regulation of drought-induced leaf senescence in perennials: A case study in field-grown Salvia officinalis L. plants. Environ. Exp. Bot. 2008, 64, 105-112. [CrossRef]

7. Bahran Kinfe, L.G.; Yosief, R.; Mehari, S.; Maekele, S.; Rao, G.S. Impact of different preservative solutions on extending vase life of rose (Rosa hybrid) cut flowers. Bioscience 2018, 11, 3562.

8. Lü, P.; Cao, J.; He, S.; Liu, J.; Li, H.; Cheng, G.; Joyce, D.C. Nano-silver pulse treatments improve water relations of cut rose cv. Movie Star flowers. Postharvest Biol. Technol. 2010, 57, 196-202. [CrossRef]

9. Mashhadian, N.V.; Tehranifar, A.; Bayat, H.; Selahvarzi, Y. Salicylic and citric acid treatments improve the vase life of cut chrysanthemum flowers. J. Agric. Sci. Technol. 2012, 14, 879-887.

10. Pun, U.K.; Ichimura, K. Role of sugars in senescence and biosynthesis of ethylene in cut flowers. Jpn. Agric. Res. Q. 2003, 37, 219-224. [CrossRef]

11. Van Ieperen, W.; Nijsse, J.; Keijzer, C.J.; Van Meeteren, U. Induction of air embolism in xylem conduits of pre-defined diameter. J. Exp. Bot. 2001, 52, 981-991. [CrossRef] [PubMed]

12. Kazaz, S.; Doğan, E.; Kılıç, T.; Şahin, E.G.E.; Seyhan, S. Influence of holding solutions on vase life of cut hydrangea flowers (Hydrangea macrophylla Thunb.). Fresenius Environ. Bull. 2019, 28, 3554-3559.

13. Asrar, A.W.A. Effects of some preservative solutions on vase life and keeping quality of snapdragon (Antirrhinum majus L.) cut flowers. J. Saudi Soc. Agric. Sci. 2012, 11, 29-35. [CrossRef]

14. Edrisi, B.; Sadrpoor, A.; Saffari, V.R. Effects of chemicals on vase life of cut carnation (Dianthus caryophyllus L. 'Delphi') and microorganisms population in solution. J. Ornam. Hortic. 2015, 2, 1-11.

15. Seyf, M.; Khalighi, A.; Mostofi, Y.; Naderi, R. Study on the effect of aluminum sulfate treatment on postharvest life of the cut rose 'Boeing' (Rosa hybrida cv. Boeing). J. Hortic. Sci. Biotechnol. 2012, 16, 128-132.

16. Elhindi, K.M. Evaluation of several holding solutions for prolonging vase-life and keeping quality of cut sweet pea flowers (Lathyrus odoratus L.). Saudi J. Biol. Sci. 2012, 19, 195-202. [CrossRef]

17. Ichimura, K.; Hisamatsu, T. Effects of continuous treatment with sucrose on the vase life, soluble carbohydrate concentrations, and ethylene production of cut snapdragon flowers. J. Jpn. Soc. Hortic. Sci. 1999, 68, 61-66. [CrossRef] 
18. Kazaz, S.; Kılıç, T.; Doğan, E.; Sekmen, Ş. Vase life extension of cut hydrangea (Hydrangea macrophylla) flowers. J. Hortic. Sci. Biotechnol. 2020, 95, 325-330. [CrossRef]

19. Rafi, Z.N.; Ramezanian, A. Vase life of cut rose cultivars 'Avalanche' and 'Fiesta' as affected by Nano-Silver and S-carvone treatments. S. Afr. J. Bot. 2013, 86, 68-72. [CrossRef]

20. Reid, M.S. Handling of Cut Flowers for Export; Proflora Bulletin; 2009; pp. 1-26. Available online: https://ucanr.edu/sites/ Postharvest_Technology_Center_/files/231308.pdf (accessed on 14 October 2021).

21. Amin, O.A. II-Effect of some chemical treatments on keeping quality and vase life of cut chrysanthemum flowers. Middle East J. Agric. Res. 2017, 6, 221-243.

22. Ichimura, K.; Shimizu-Yumoto, H. Extension of the vase life of cut roses by treatment with sucrose before and during simulated transport. Bull. Natl. Inst. Flor. Sci. 2007, 7, 17-27.

23. Elgimabi, M.E.N.E. Vase life extension of Rose cut flowers (Rosa Hybrida) as influenced by silver nitrate and sucrose pulsing. Am. J. Agric. Biol. Sci. 2011, 6, 128-133. [CrossRef]

24. Yagi, M.I.; Eldeen, M.; Elgemaby, N.E. Effect of bactericides and sucrose pulsing on longevity and vase life of rose cut flowers. Int. J. Sci. Basic Appl. Res. 2014, 14, 117-129.

25. Norikoshi, R.; Shibata, T.; Niki, T.; Ichimura, K. Sucrose treatment enlarges petal cell size and increases vacuolar sugar concentrations in cut rose flowers. Postharvest Biol. Technol. 2016, 116, 59-65. [CrossRef]

26. Ku, B.S.; Cho, M.S. Vase life and quality as affected by various holding solution of cut Hydrangea macrophylla. Flower Res. J. 2014, 22, 12-20. [CrossRef] 